\section{Commentary: Malacia got you down? Unwind with a helical stent}

Douglas M. Overbey, MD,

Joseph W. Turek, MD, PhD, and

Nicholas D. Andersen, MD

Severe cases of pediatric tracheobronchomalacia can require tracheostomy, prolonged periods of positive pressure ventilation, and/or invasive surgical procedures intended to stabilize the airways. Prior attempts at therapeutic internal airway stenting to avoid the need for positive pressure ventilation in children have been largely unsuccessful due to poor mucous clearance, fragmentation, and diameter reduction. Surgical approaches are invasive and carry a significant failure rate along with risks of fistulization and other complications. ${ }^{1,2}$ Mondal and colleagues ${ }^{3}$ describe the in vivo evaluation of a new airway stent designed to overcome some of these challenges.

For the design of the stent, the authors borrowed from the wine cabinet (Figure 1) and replicated a corkscrew design constructed from nitinol. The helical nickel titanium wire stents provide radial support set for a certain airway pressure, and provide spaces between the coils for normal mucociliary clearance of the respiratory epithelium. Once in place, the stent is low profile and can be removed with little trauma due to a ball forceps rotational removal system.

Five experimental swine were utilized for 4 weeks, the first 3 with the stent in place and another week without. The stents were tolerated and removed without complication, despite most showing some degree of endothelialization. One migration was noted but remained within the trachea. Polytetrafluoroethylene discs were used to evaluate airway clearance, which was deemed intact. Pathologic

\footnotetext{
From Duke Children's Pediatric \& Congenital Heart Center, Duke Children's Hospital, Durham, NC

Disclosures: The authors reported no conflicts of interest.

The Journal policy requires editors and reviewers to disclose conflicts of interest and to decline handling or reviewing manuscripts for which they may have a conflict of interest. The editors and reviewers of this article have no conflicts of interest.

Received for publication April 19, 2020; accepted for publication April 21, 2020; available ahead of print May 1, 2020.

Address for reprints: Nicholas D. Andersen, MD, Division of Cardiovascular and Thoracic Surgery, Duke University Medical Center, 2301 Erwin Rd, DUMC 3474, Durham, NC 27710 (E-mail: Nicholas.Andersen@Duke.edu).

J Thorac Cardiovasc Surg 2021;161:e61-2

$0022-5223 / \$ 36.00$

Copyright (C) 2020 by The American Association for Thoracic Surgery

https://doi.org/10.1016/j.jtcvs.2020.04.065
}

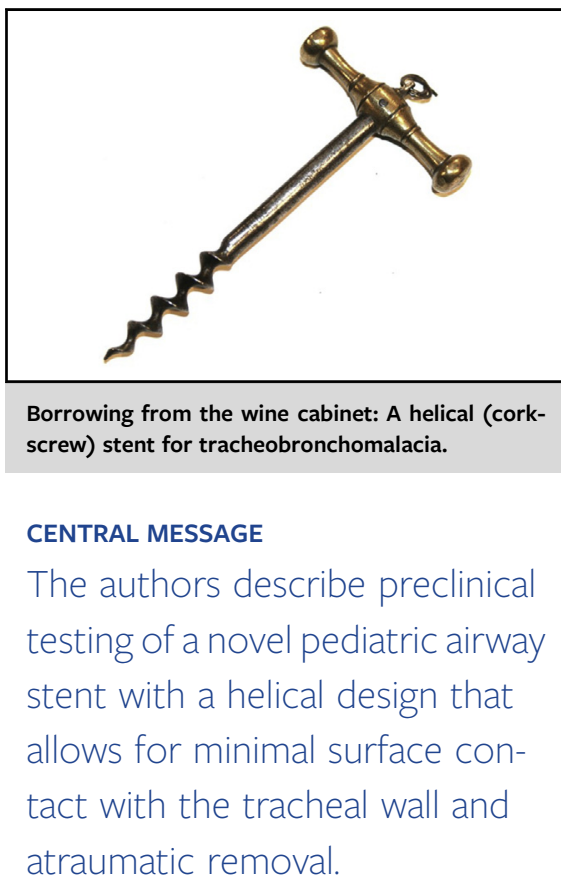

review showed inflammation and granulation at the sites of stent wire contact, but intervening segments were without significant tissue damage and $<12 \%$ of the area was unciliated.

The strength of this study is the longitudinal live animal model with multiple static and dynamic measurements of native airway function following stent placement. The stent design also appears to have clear advantages over existing technology for airway applications. The limitations of the study and device included 1 migration and a relatively low sample size in a model with inevitable differences from human airway anatomy and lack of initial demonstrable tracheobronchomalacia.

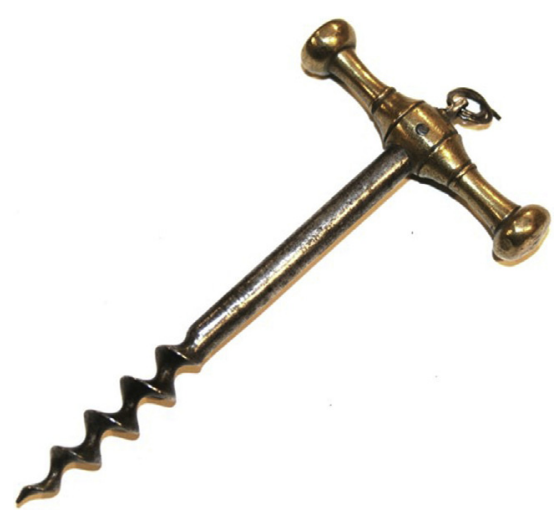

FIGURE 1. A corkscrew inspired a novel helical stent for tracheobronchomalacia. 
The diameters of the pig tracheas in this study (range, 11$14 \mathrm{~mm}$ ) are larger than human neonatal and infant airways that may require intervention before age 1 year (range, 5-6 mm). Further dynamic longitudinal studies in smaller animals may be needed to determine whether the stent accomplishes its intended goal of preventing pediatric airway collapse.

These preclinical results show promise for a new type of stent with successful initial performance in an animal airway model. The potential influence of this new device is excellent, and it could fill a critical vacancy where no good current options exist. This represents another example of important surgical innovation from an exemplary team, and further clinical progress is eagerly anticipated.

\section{References}

1. Kamran A, Jennings RW. Tracheomalacia and tracheobronchomalacia in pediatrics: an overview of evaluation, medical management, and surgical treatment. Front Pediatr. 2019;7:512.

2. Valerie EP, Durrant AC, Forte V, Wales P, Chait P, Kim PC. A decade of using intraluminal tracheal/bronchial stents in the management of tracheomalacia and/or bronchomalacia: is it better than aortopexy? J Pediatr Surg. 2005;40: 904-7.

3. Mondal A, Ha J, Jo VY, Wu F, Kaza AK, Dupont PE. Preclinical evaluation of a pediatric airway stent for tracheobronchomalacia. J Thorac Cardiovasc Surg. 2021;161:e51-60.
See Article page e51.

\section{Commentary: Toward a more ideal pediatric airway stent for tracheobronchomalacia}

\author{
Roosevelt Bryant III, MD
}

The first clinical deployment of a pediatric airway stent was in 1988 and was reported by Loeff and colleagues. ${ }^{2}$ Since that time, an array of airway stents have developed to treat complex airway disease in children. Pediatric-specific applications of airway stents include use after tracheal reconstruction for congenital tracheal stenosis ${ }^{3}$ and for tracheobronchomalacia ${ }^{4}$ not responsive to medical therapy. However, the ideal pediatric airway stent has yet to be developed. The ideal airway stent for pediatric patients should be easy to place, should support the airway without the development of significant complications, and should be easy to remove to allow maximal growth of the airway. ${ }^{3}$

\footnotetext{
From the Division of Congenital Heart Surgery, The Heart Center, Phoenix Children's Hospital, Phoenix, Ariz.

Disclosures: The author reported no conflicts of interest.

The Journal policy requires editors and reviewers to disclose conflicts of interest and to decline handling or reviewing manuscripts for which they may have a conflict of interest. The editors and reviewers of this article have no conflicts of interest.

Received for publication April 3, 2020; revisions received April 3, 2020; accepted for publication April 3, 2020; available ahead of print April 18, 2020.

Address for reprints: Roosevelt Bryant III, MD, Heart Transplantation and Mechanical Circulatory Support, Phoenix Children's Hospital, 1919 E Thomas Rd, Phoenix, AZ 85016 (E-mail: rbryant1@phoenixchildrens.com).

J Thorac Cardiovasc Surg 2021;161:e62-3

$0022-5223 / \$ 36.00$

Copyright (c) 2020 by The American Association for Thoracic Surgery

https://doi.org/10.1016/j.jtcvs.2020.04.035
}

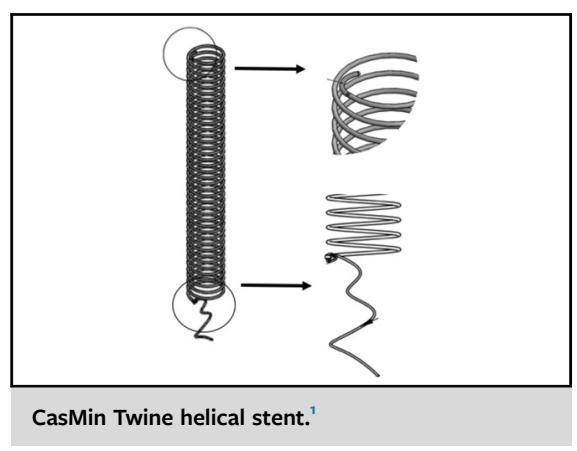

CENTRAL MESSAGE

The helical Niti-S airway stent

shows promise as a more ideal prosthesis for the management

of tracheobronchomalacia.

Potential stent-related complications include migration, granulation tissue formation, mucus formation, and infection, ${ }^{5}$ particularly when granulation tissue develops. Despite the wide array (metallic, ${ }^{6}$ silicon, ${ }^{7}$ bioabsorbable ${ }^{8}$ ) of pediatric stents available, none of them is ideal. The known complications associated with these devices have led to a stent-related mortality rate as high as $12.9 \%$. $^{7}$ Furthermore, the radial force used to keep certain kinds of stents in place has been shown to damage the microcirculation and serves as the nidus for mucosal injury and subsequent granulation tissue formation. ${ }^{9,10}$ 